\title{
Poéticas Biográficas do Corpo Explantado: Notas Sobre Três Ensaios Visuais Brasileiros
}

\author{
Roberta Gobbi Baccarim
}

Angie Gomes Biondi

\author{
Programa de Pós-Graduação em Comunicação e \\ Linguagens, Faculdade de Ciências Sociais Aplicadas, \\ Universidade Tuiuti do Paraná, Curitiba, Brasil \\ https://orcid.org/0000-0002-3403-5979 \\ Programa de Pós-Graduação em Comunicação e \\ Linguagens, Faculdade de Ciências Sociais Aplicadas, \\ Universidade Tuiuti do Paraná, Curitiba, Brasil \\ https://orcid.org/0000-0002-0486-1081
}

\begin{abstract}
O presente texto propõe uma reflexão sobre as imagens do corpo feminino através dos ensaios visuais de três artistas brasileiras contemporâneas: Karka Keiko, Fiamma Viola e Maria Luísa Andrade. Os apontamentos tecidos às imagens estão interligados por três notas principais: a primeira discute as tematizações do corpo feminino que figuram nos contextos midiáticos, artísticos e culturais compondo uma agenda de pesquisa propriamente feminista; a segunda observa como as artistas emprestam seus corpos explantados, submetidos aos procedimentos cirúrgicos, para a construção de um trabalho de elaboração criativa e narrativa de si através das imagens; e a terceira traça os pontos de ruptura estético-políticos provocados pelas imagens ensaísticas indicando o recurso poético como um gesto de resistência em uma sociedade inundada por selfies. Ao desenvolver a discussão, é possível observar como este tipo de conteúdo circula tanto nas elaborações visuais e artísticas das galerias e museus, quanto na forma de postagens, através de conhecidos sites de redes sociais, de modo a adquirir maior alcance do olhar público. Capazes de instaurar a criação de uma cena enunciativa voltada para as telas, os corpos das mulheres submetidos ao explante mamário propõem refletir acerca das novas formas de vínculos do olhar sobre o corpo feminino.
\end{abstract}

Palavras-chave: corpo, biografia, feminismo, imagem

\section{Biographical Poetics of the Explanted Body: Notes on Three Brazilian Visual Essays}

This text proposes a reflection about the images of the female body through the visual essays of three Brazilian artists: Karka Keiko, Fiamma Viola and Maria Luísa Andrade. Three main annotations were made to the images under analysis: the first discusses the themes of the female body that figure in the media, artistic and cultural contexts that make up a specifically feminist research agenda; the second observes how the artists lend their explanted bodies, submitted to surgical procedures, to build a work of creative and narrative elaboration of themselves through the images; and the third, traces the aesthetic-political breaking points caused by the essayistic images indicating the poetic resource as a gesture of resistance in a society flooded with selfies. In developing the discussion, we can observe that this content travels both in visual and artistic elaborations, at galleries and museums, and in the form of postings, through renowned digital platforms and social networks to expand the reach of the public gaze. They can create an enunciative scene on the screens, and the bodies of women who have undergone breast explantation suggest a reflection on the new forms of linking the gaze on the female body.

Keywords: body, biography, feminism, image

Submetido: 09/11/2021 | Revisto: 29/11/2021 | Aceite: 29/11/2021 | Publicado: 22/12/2021 


\section{As Tematizações do Corpo Próprio em uma Agenda de Pesquisa Feminista}

Em sua pesquisa sócio historiográfica mais recente, Margareth Rago (2011) indica que foi no início dos anos de 1980 que diversos temas femininos retornaram com força à agenda das pesquisas brasileiras. As abordagens eram muitas e diferenciadas, e tratavam de aspectos desde "a presença das mulheres nas greves, manifestações operárias e outras formas de luta social até a bruxaria, a prostituição, a loucura, o aborto, a maternidade e o parto, a saúde, a sexualidade" (Rago, 2011, p. 2). No campo das artes, especificamente, o corpo da mulher já figurava em diferentes formatos como happenings, performances, exposições body art, entre outras modalidades difundidas em outros países do ocidente, e promovidas também no Brasil. Assim, segundo Rago (2011), mesmo em descontinuidades, o corpo feminino sempre foi objeto da atenção de diferentes campos, estudos e discursos.

Enquanto alvo de disputas, confrontos e apropriações, o corpo feminino cisgênero serviu, igualmente, às investidas de um mercado estético que também crescia de maneira exponencial com a abertura do país aos produtos de consumo estrangeiros no mesmo período. Um amplo segmento da indústria da beleza viu resplandecer um mercado consumidor brasileiro, que rapidamente assimilou tanto os padrões quanto os produtos que recebia. Deste modo, a busca pela perfeição do corpo feminino adquiriu tamanha importância que, segundo o relatório mundial de cirurgias estéticas (International Society of Aesthetic Plastic Surgery, 2020), em 2019, o Brasil ocupava a primeira posição no ranking dos procedimentos, perfazendo um total de 1.493.673, seguido, em segundo lugar, pelos Estados Unidos.

Entre as modalidades cirúrgicas mais procuradas pelas mulheres, a lipoaspiração ocupava o primeiro lugar, seguida pelo aumento dos seios com a colocação de próteses de silicone. Ainda segundo a pesquisa (International Society of Aesthetic Plastic Surgery, 2020), o conhecido combo "cinturinha, barriga negativa e peitão"1 dita o que há de mais desejado em termos de aperfeiçoamento corporal feminino. Estes dados, comparados ao número de cirurgias estéticas em homens, demonstram ainda que as mulheres brasileiras são as que mais custeiam os procedimentos cirúrgicos, além de investirem em outros produtos de embelezamento corporal.

Promover uma busca incessante pelo mito da beleza, segundo Naomi Wolf (1990/1992), é ainda uma maneira de controle social que se dá através de uma política visual do corpo favorecendo um sistema, simultaneamente econômico, ideológico e cultural, que submete o corpo feminino ao olhar público e aos valores cisheteropatriarcais que se naturalizam como discurso hegemônico, constantemente reproduzido e legitimado. Segundo a pesquisadora, o ideal de beleza ampara-se não só no desenvolvimento tecnológico da medicina estética e nos avanços da indústria cosmética, mas na divulgação em massa de imagens que supervalorizam um padrão corporal feminino tornando-o desejável, um objeto de consumo.

Vale ressaltar que na corrida pelo corpo feminino ideal há muito que a publicidade se constitui um campo para a afirmação de normas e desejos que se realizarão (sempre como promessa) a partir de um modelo de consumo que associa felicidade, sucesso, juventude e beleza, consolidando-o como mercadoria que retroalimenta tais pseudonecessidades indissociáveis. Consumir um ideal de beleza equivaleria à obtenção de felicidade, sucesso e juventude; o corpo feminino desejável é ainda aquele que concentra maior valor de atenção e, supostamente, libido.

Desta maneira, desejo e consumo são orientados por um modelo produtor, regulador, de um corpo feminino que não é afirmado apenas pelo alcance de padrões, hoje cada vez mais acessíveis, mas pela afirmação constante do olhar público. Não basta esculpir o corpo para alcançar um molde idealizado, mas se manter enquanto um corpo desejável ao olhar, de modo que, ser visto passa a ser o fator último deste modelo. 
No entanto, segundo Paula Sibilia (2015, 2016), no contexto da sociedade atual, não se pode mais falar de um simples estágio de julgamento pela imagem ou de uma crítica ao consumismo desenfreado pela imagem, como outrora se ocuparam certas vertentes sociológicas, tais como, a cultura do espetáculo em Guy Debord (desde os anos de 1940), por exemplo, ou ainda de uma política da exibição de si como formadora identitária do self, como em Charles Taylor (nos anos de 1990), mas deve-se refletir acerca de uma política da visibilidade que, cada vez mais, coloca o sujeito em uma obrigatoriedade de exibição associada ao rigor estético e à habilidade narrativa. Para a autora (Sibilia, 2015, 2016), atualmente, há um investimento na imagem do corpo feminino que seria tão ou mais importante que o investimento no aperfeiçoamento do próprio corpo, ao longo de décadas.

Ao mesmo tempo em que circulam, nos diferentes contextos, imagens que ainda valorizam o corpo feminino pelo atendimento aos padrões de beleza convencionais há, contrariamente, uma profusão de imagens que valorizam o corpo feminino pelo seu potencial de desconstrução ou inadequação a estes mesmos padrões (Nead, 1998). Contudo, nos dois casos, o que prevalece é certa exibição performada do corpo feminino.

Nas últimas décadas, têm se ampliado enormemente os limites do que se considera válido mostrar no espaço público, particularmente no que se refere à sexualidade e, em especial, à nudez dos corpos femininos. Cada vez mais distantes dos pudores típicos dos séculos XIX e $\mathrm{XX}$, em campos que vão da publicidade e dos videoclipes até as artes visuais, performáticas e cênicas, passando pelos autorretratos que se multiplicam nas redes sociais da internet, parece que se mostrar sem roupas está na moda. Inclusive, aderindo a certo ativismo de nova geração, mulheres de toda classe exibem-se nuas em nome de uma multiplicidade de causas consideradas "nobres", tais como a ecologia, o direito à contracepção, a liberdade de expressão ou o respeito às diferenças culturais. Nesse universo figuram atrizes e modelos famosas, mas também todo tipo de "anônimas" que publicam seus selfies na internet, chegando até aos coletivos organizados como Femen, Marcha das Vadias, Free the Nipple ou Pedalada Pelada, entre muitos outros. (Sibilia, 2015, p. 172)

Para Sibilia (2016), esta centralidade na exposição do corpo se relaciona a um novo "giro do eu", que muda do íntimo para o éxtimo, cuja dialética forja uma subjetividade hoje voltada ao exterior e que remodela o próprio estatuto da imagem, pois "inscreve as imagens em outro regime de verdade e suscita outro horizonte de expectativas" (p. 30).

A experiência de si como um eu se deve, portanto, à condição de narrador do sujeito: alguém que é capaz de organizar sua experiência na primeira pessoa do singular. Mas este não se traduz unívoca e linearmente através de suas palavras, traduzindo em texto alguma entidade que precederia o relato e seria "mais real" do que a mera narração. Em vez disso, a subjetividade se constitui na vertigem desse córrego discursivo, é nele que o eu de fato se realiza. Pois usar palavras e imagens é agir: graças a elas podemos criar universos e com elas construímos nossas subjetividades, nutrindo o mundo com um rico acervo de significações. (Sibilia, 2016, p. 31)

A conjunção de relatos pessoais acompanhados de imagens de fragmentos da vida cotidiana, conforme Sibilia (2016), parece reafirmar tanto a dimensão visível do sujeito quanto moldar uma subjetividade que se constrói para/pelo olhar público. Daí ser possível notar, atualmente, um número crescente de relatos de mulheres que apresentam, não apenas os momentos de realização de cirurgias e outros procedimentos estéticos, mas também as reações adversas, rejeições, doenças, retiradas de próteses, cicatrizes e marcas como o reverso desta mesma experiência corporal, sendo imprescindível manter a exposição de si, do seu corpo, como imagem principal. Outrora classificadas pela alcunha pejorativa de "siliconada ou turbinada", inúmeras mulheres que buscaram atender ao padrão do corpo feminino desejável hoje têm revelado seu histórico de 
procedimentos para aumentar e modelar os seios (Sant'Anna, 2014), mas que, por diversos motivos, decidiram por sua retirada de modo a recolocar o corpo como mediador de novas experiências, propriamente estéticas e subjetivas.

Neste texto, indicamos os trabalhos visuais de três mulheres brasileiras que usaram tanto o espaço da arte quanto das mídias para fazer de suas experiências de explante um novo processo de escritura através do corpo, compondo um tipo de conteúdo afeito ao que a pesquisadora Margareth Rago (2013) classifica como "escritas de si" (p. 42). Assim, observamos que este conteúdo circula tanto nas elaborações visuais e artísticas, presentes em galerias e espaços de arte, quanto na forma de postagens, através de plataformas digitais e sites de redes sociais, e que adquirem cada vez mais alcance por conta das replicações, compartilhamentos e visualizações capazes de instaurar a criação de uma cena enunciativa voltada para as telas, que permite adensar novas formas de vínculos ao olhar sobre o corpo feminino exposto.

\section{O Corpo Explantado Como uma Escrita de Si}

Embora seja um tema ainda pouco discutido no Brasil, alguns veículos de imprensa 2 e outros meios midiáticos, sobretudo ligados ao universo médico e especializado, dedicaram espaços para informar sobre uma nova doença, associada ao uso de próteses de silicone, conhecida como síndrome autoimune induzida por adjuvante, mais famosa por breast implant illness e síndrome ASIA. De acordo com a literatura médica, o processo de adoecimento físico pode iniciar pouco tempo após o implante das próteses de silicone e inclui complicações relacionadas ao uso deste material, tais como dor nas articulações, queda de cabelo, alteração do funcionamento intestinal, cansaço excessivo, além de insônia, ansiedade e outros transtornos.

No entanto, a doença, embora cada vez mais diagnosticada entre as pessoas que implantaram, ainda é pouco conhecida do público em geral e, menos ainda, divulgada nos meios de comunicação do país. Deste modo, muitas mulheres que explantaram as próteses mamárias porque desenvolveram a síndrome têm buscado outros espaços para dar visibilidade às suas experiências.

Na pesquisa em andamento, é possível notar diversos casos de mulheres que relataram suas experiências com a doença e o explante através de páginas pessoais na internet, em perfis em sites de redes sociais, ensaios visuais, trabalhos artísticos, entre outros. Buscar espaços de expressão diferenciados e, muitas vezes, complementares, para expor os diversos relatos pessoais sobre todo o processo de adoecimento e explante figura como recurso expressivo, subjetivo e político dessas mulheres. Nos relatos postados nas redes sociais, ainda mais explicitamente, as mulheres ora enfatizam o adoecimento e a toxicidade do silicone, ora questionam o consumo acrítico dos padrões de beleza que objetifica e aliena.

Segundo elas, aderir ao ideal do corpo acabou por encerrar suas subjetividades em modelos impossíveis causando prejuízos na aceitação e valorização de si mesmas. Daí a necessidade daquelas que passaram pelo adoecimento e cirurgia de explante decidirem expor seus corpos marcados, na arte e na mídia, como forma de elaboração de outra escrita de si, fazendo do próprio corpo um elemento importante a reivindicar outra política de visibilidade do corpo feminino.

Karla Keiko é uma artista brasileira que relata sua experiência de violências médicas relacionadas ao uso das próteses de silicone e desrespeito à autonomia nas decisões sobre seu corpo. Suas produções artísticas e falas assumem uma postura crítica em relação aos motivos que levam as mulheres a optarem pelo uso das próteses, relatando também a deslegitimação social de um sofrimento psicológico encarcerado em um corpo considerado belo.

A artista apresenta dois trabalhos videográficos, cujas performances usam seu próprio corpo em movimentos coreografados. O trabalho intitulado Pendências (2017) apresenta a cirurgia plástica mamária feita por Karla, tendo sido planejada durante o período de sua residência artística, e 
filmada anteriormente ao explante. Pendências foi apresentado na Bienal de Curitiba, no espaço do Itaú Cultural, em 2017, mas suas fotografias também estão disponíveis em seu perfil pessoal, na plataforma Flickr.

Nas imagens, ela aparece despida e com os cabelos raspados, manipulando os seios em movimentos que convocam certo estranhamento ao olhar, já que enfatizam a plasticidade das mamas como um mero órgão biológico. Seu corpo é exibido em uma espécie de ritmo intercalado por outras imagens de frutas e alimentos arredondados, que são rasgados, partidos e manipulados, de uma maneira pouco cuidadosa, remetendo a certa associação entre esses materiais orgânicos que, igualmente, são modificados e modelados pela ação humana.

Pelas imagens em cotejo também é possível observar que a artista utilizou a repercussão desse trabalho para dar visibilidade aos sofrimentos psicológicos vivenciados pelas outras mulheres que buscam corresponder a um padrão de beleza inatingível. Em uma imagem do ensaio, Karla aparece de perfil, em um ambiente envolto em uma iluminação vermelha, nostálgica, deixando à mostra apenas seu busto sem a presença dos braços. Os seios estão expostos sob uma camisa rasgada cuja inscrição "em exibição" parece reiterar que o corpo feminino se limita à centralidade dos seios nus. Os desenhos tatuados no busto são tentativas de recriar seu corpo alterado pela cirurgia; uma forma de reescrever, com ilustrações, sobre os traços cirúrgicos.

O corpo explantado de Karla também aparece em outro trabalho intitulado La Danza de Su Hijo Dentro Suyo (A Dança do Seu Filho Dentro de Si; 2017). Na obra, ela aparece vestida com uma camisola branca e transparente, poucos meses pós o explante, exibindo a sua primeira gestação. Pelas imagens, é possível notar, em seu corpo, as cicatrizes provenientes das cirurgias, a de implante e a troca de próteses de silicone, às quais Karla havia se submetido. O seio nu explantado de Karla é capturado em dois momentos como se costurasse, pelas imagens, um antes e um depois.

Fiamma Viola é uma brasileira, residente na Itália, que obteve certa repercussão e notoriedade após intensa atuação na rede social Instagram, quando relatou, em seu perfil, o processo de adoecimento físico e psicológico vivenciado pelo uso das próteses de silicone. Sua produção artística também acabou voltada para a exposição de sua experiência pessoal e, em um dos seus trabalhos visuais, ela utilizou o próprio sangue armazenado do dreno pós cirúrgico para, a partir das próteses de silicone removidas, fazer imagens de estêncil que resultaram na série Despeitos (2019).

Ao contrário de Keiko, Viola escolhe não expor seu corpo explantado em fotografias, exceto por imagens publicadas em matérias sobre o seu processo cirúrgico e artístico, onde exibe suas cicatrizes ainda com as próteses de silicone. Contudo, nas imagens produzidas, ela enfatiza o uso dos vestígios de sua experiência de sofrimento, usando suas próteses e seu sangue para criar novas imagens que buscam dialogar com o olhar do espectador e chamar a atenção ao que resta, afinal, desse processo.

Convidado a olhar o avesso, o espectador das imagens de Viola atenta à outra forma de escritura do corpo feminino que superdimensiona os seios repintados com sangue. Fragmentados e superpostos, as partes visíveis dos seios gotejam lágrimas de sangue, exibem cicatrizes e marcas resultantes das cisões como costuras que não conseguem se fechar completamente. Há um desconforto proposital no estêncil produzido por Viola.

Maria Luísa Andrade, artista brasileira, procura transformar sua experiência de adoecimento em subsídio para arte visual. Ela criou um site, denominado Relato em Carne Crua (2019), onde expõe o adoecimento através de textos e fotografias que registram seu corpo explantado. Subdivido em cinco sessões: "Deslumbre", "Veneno", "Loucura", "Liberdade" e "Cura", o relato visual criado por Maria Luísa narra a experiência dolorosa que teve, do implante à remoção mamária.

Nas fotografias que compõem o ensaio, Maria Luísa aparece nua, em momentos capturados pela 
câmera, onde usa apenas uma máscara de gás e segura as próteses de silicone retiradas do seu corpo (Figura 1). Ao mesmo tempo em que expõe as cicatrizes nos seios e ergue as próteses retiradas, ela denuncia o potencial tóxico do material.

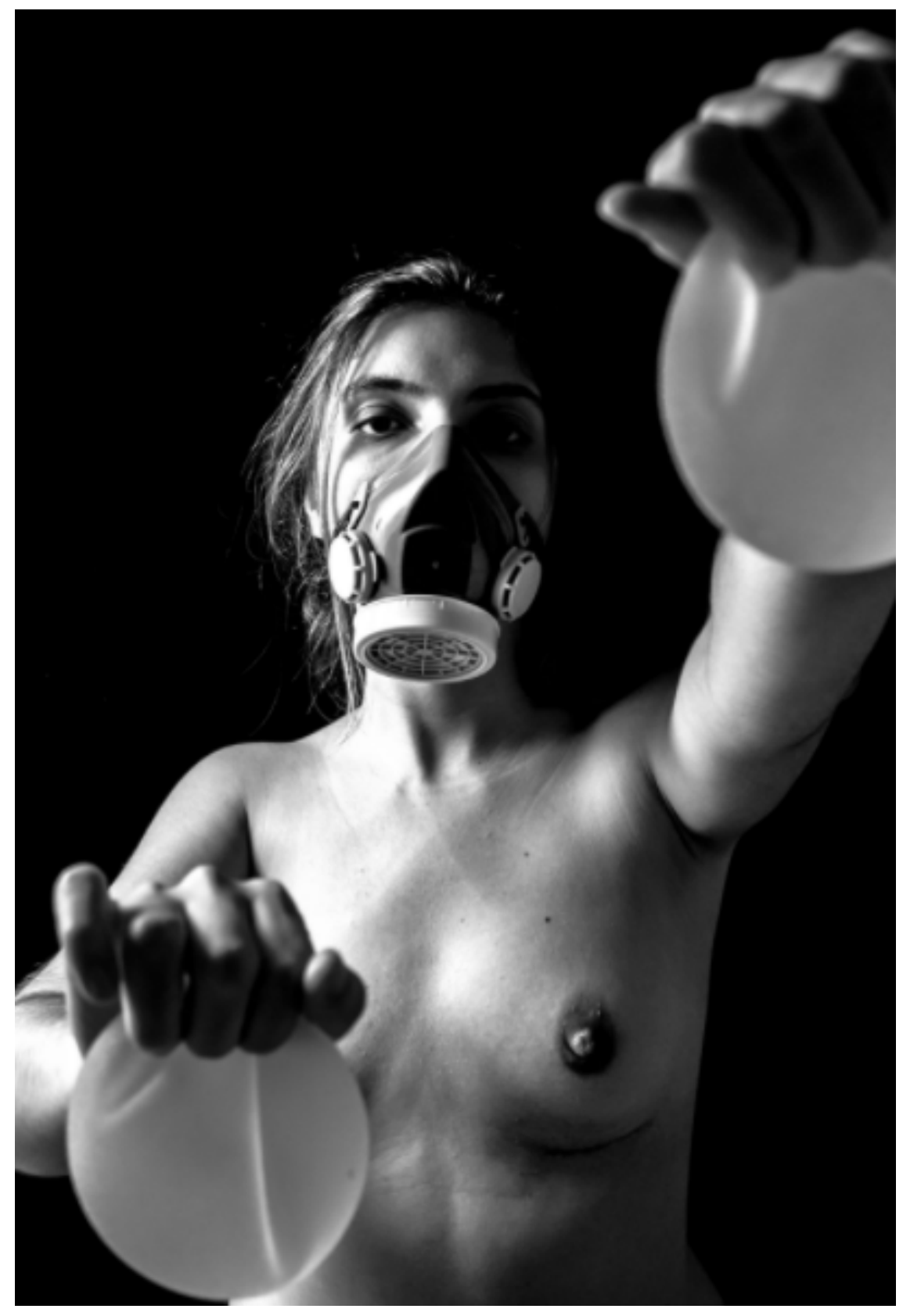

Figura 1. Maria Luísa Andrade. Relato em Carne Crua, 2019 Créditos. Rafael Lira Ribeiro da Silva (De Relato em Carne Crua, Maria Luísa Andrade, 2019. Reimpresso com autorização de Maria Luísa Andrade)

Em outra imagem (Figura 2), vê-se uma mão calçada com luva branca cirúrgica fechar a sua boca e, em seu busto nu, aparecem escritas as propriedades químicas que compõem as próteses de silicone misturadas às marcações que localizam as partes dos seios que serão alteradas. Como uma denúncia, a imagem chama a atenção sobre a dificuldade de acesso às informações mais precisas sobre os potenciais malefícios do material que será enxertado no corpo da mulher. 


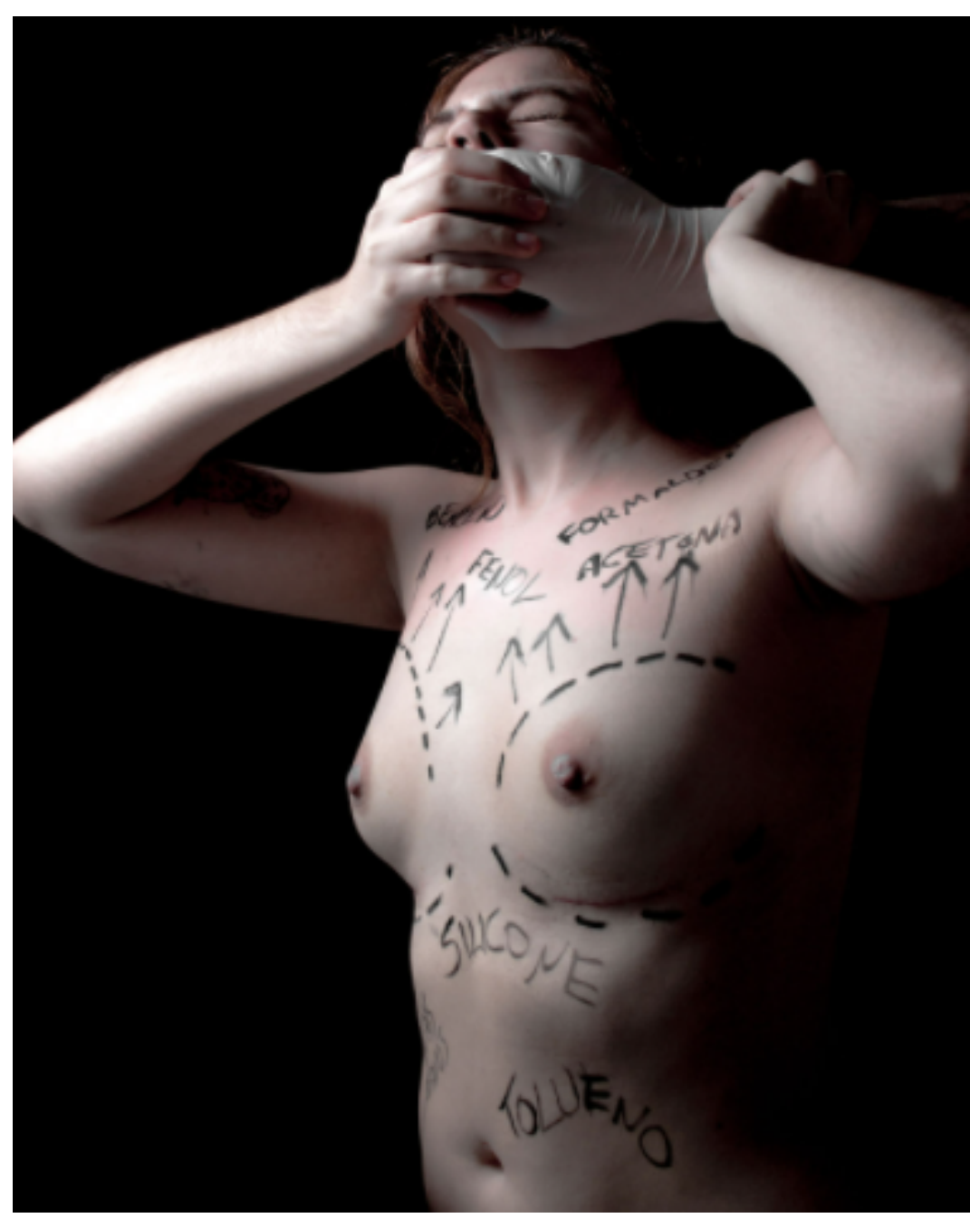

Figura 2. Maria Luísa Andrade. Relato em Carne Crua, 2019 Créditos. Rafael Lira Ribeiro da Silva (De Relato em Carne Crua, Maria Luísa Andrade, 2019. Reimpresso com autorização de Maria Luísa Andrade)

Todas as fotos elaboradas no relato de Maria Luísa apontam para a apresentação de uma fala que se pretende legítima e que questiona a autoridade médica quando elide informações sobre as consequências prejudiciais do silicone à saúde da mulher. Vítima de uma idealização estética e do posicionamento médico, o corpo feminino é assim mantido subjugado. O teor de denúncia a estes procedimentos é exposto pelo relato de Maria Luísa, que tenta sobrepor sua voz emprestando seu próprio corpo marcado e adoecido.

\section{Rupturas dos Padrões Heteronormativos nas Imagens da Arte e da Mídia}

As imagens observadas nos trabalhos visuais de Karla Keiko, Fiamma Viola e Maria Luísa Andrade inscrevem as três mulheres artistas em posição de participação ativa, como sujeitos que refletem e, potencialmente, modificam as experiências corporais através da formulação de novas imagens que ativam o funcionamento das escritas de si, como proposto por Rago (2013). Portanto, elas não figuram apenas como personagens nos trabalhos visuais, mas são também protagonistas. Autoras e personagens, elas se apresentam a si próprias inscrevendo seus corpos como um agente artístico, estético, mas também político, através de uma tessitura tanto poética quanto biográfica.

O argumento que defendemos é que os ensaios visuais observados neste texto não pretendem reivindicar uma classificação categórica do gênero autobiográfico, mas partem do corpo como fonte 
de uma escritura (auto)biográfica, tomam o corpo como um elemento de contraposição reflexiva e epistemológica.

Em acordo com as considerações de Damião (2020), devemos considerar este tratamento da corporeidade da mulher como uma experiência desdobrada no sentido da construção de uma subjetividade múltipla e em processo tanto artístico quanto político. Para ela, trata-se da compreensão de "uma corporeidade relacionada a um processo de desafio em transpor lugares e (de)compor identidades” (Damião, 2020, p. 159).

Este modo de escritura visual que busca a desconstrução do feminino mobilizando o próprio corpo pode ser encontrado nos trabalhos artísticos de outras mulheres como ORLAN, Anette Messager, Cindy Sherman, Susanne Ohmann. Nas fotografias de ORLAN, por exemplo, pode-se notar certa ênfase na subversão dos signos do corpo feminino como objeto de consumo sexualmente reificado. A artista estende sua crítica também à circulação massiva de imagens e selfies que, continuamente, insistem em repor a mulher no lugar sacrificial retomado pelos rituais do martírio e dor em nome da santificação ou da beleza ideal e, para isso, usa seu próprio corpo. As diversas figurações de si são cuidadosamente registradas em autorretratos, onde dispõe do seu próprio corpo como uma superfície de criação e reelaboração de modo a "transformar em ritual a cena cirúrgica; cena de autoimolação que estetiza o corpo contrariamente à norma estetizante" (Damião, 2020, p. 162).

Nos ensaios visuais observados neste texto, as mulheres que buscaram modelar seus corpos aos padrões de beleza corporal aderindo aos implantes de silicone são as mesmas que hoje expõem seus corpos como imagem, apresentando-os através de outros modos de escritura, explorando novas sensorialidades, criando outras interfaces visuais potencialmente capazes de interrogar o olhar e a reflexão sobre os padrões sociais impostos ao corpo feminino. A grande interrogação provocada pelas imagens seria: qual corpo desejam para si mesmas?

As imagens trazidas por Karla Keiko, Fiamma Viola e Maria Luísa Andrade são apenas exemplares de tantas outras experiências de adoecimento, dor e rejeição vivenciadas por muitas mulheres que decidiram desfazer o padrão, destituir a norma, re-figurar o corpo. Ao subverterem as imagens padronizadas dos corpos femininos reificados e radicalizados pelas intervenções cirúrgicas através de novas proposições imagéticas dos seus corpos cicatrizados, mutilados e adoecidos, elas propõem, ao corpo explantado, um gesto político de resistência.

\section{Agradecimentos}

A Maria Luisa Andrade e Rafael Lira.

\section{Notas Biográficas}

Roberta Gobbi Baccarim é professora do Departamento de Psicologia da Universidade Tuiuti do Paraná. É doutoranda do programa de Pós-Graduação em Comunicação e Linguagens da Universidade Tuiuti do Paraná. Investigadora do grupo de pesquisa Corpo, Imagem e Sociabilidade (Universidade Tuiuti do Paraná/Conselho Nacional de Desenvolvimento Científico e Tecnológico), Brasil.

\section{ORCID: https://orcid.org/0000-0002-3403-5979}

Email: roberta.gobbi@gmail.com

Morada: Rua Sydnei Rangel Santos, 238. Santo Inácio. CEP.82.010-330. Curitiba - Paraná, Brasil

Angie Gomes Biondi é professora do programa de Pós-Graduação em Comunicação e Linguagens da Universidade Tuiuti do Paraná. É doutora em comunicação social pela Faculdade de Filosofia e 
Ciências Humanas da Universidade Federal de Minas Gerais. Fez um pós-doutoramento em artes pela Faculdade de Letras, Université du Québec à Montréal, Canadá. É também coordenadora do grupo de pesquisa Corpo, Imagem e Sociabilidade (Universidade Tuiuti do Paraná/Conselho Nacional de Desenvolvimento Científico e Tecnológico), Brasil.

ORCID: https://orcid.org/0000-0002-0486-1081

Email: angiebiondina@gmail.com

Morada: Rua Sydnei Rangel Santos, 238. Santo Inácio. CEP.82.010-330. Curitiba - Paraná, Brasil

\section{Notas}

1. Expressão popularizada no Brasil com o surgimento do chamado low pressure fitness, que se refere a um tipo de ginástica abdominal hipopressiva, que objetiva acabar com a gordura abdominal para definição de uma silhueta extremamente delgada.

2. Dentre os jornais de maior circulação no Brasil, em 2019, apenas A Folha de São Paulo, dedicou extensa reportagem sobre a síndrome autoimune induzida por adjuvante (Geraldo, 2019).

\section{Referências}

Damião, C. M. (2020). Corporeidade, nomadismo e performance. Artefilosofia, 15, 158-170.

Geraldo, N. (2019, 25 de setembro). 'Explante' de silicone: Elas tiraram próteses e se acham mais bonitas. Folha de São Paulo. https://www1.folha.uol.com.br/equilibrioesaude/2019/09/explante-desilicone-elas-tiraram-proteses-e-se-acham-mais-bonitas.shtml

International Society of Aesthetic Plastic Surgery. (2020). ISAPS global statistics.

https://www.isaps.org/medical-professionals/isaps-global-statistics/

Nead, L. (1998). El desnudo femenino. Tecnos.

Rago, L. M. (2011). Feminismos e história: Um encontro com o passado. In M. de M. Ferreira (Ed.), Anais do XXVI Simpósio Nacional da ANPUH - Associação Nacional de História (pp. 1-8). Editora ANPUH.

http://www.snh2011.anpuh.org/resources/anais/14/1300631785_ARQUIVO_textoanpuh2011.pdf

Rago, L. M. (2013). A aventura de contar-se: Feminismos, escrita de si e invenções da subjetividade. Editora Unicamp.

Sant’Anna, D. B. (2014). História da beleza no Brasil. Contexto.

Sibilia, P. (2015). A nudez auto-exposta na rede: Deslocamentos da obscenidade e da beleza?

Cadernos Pagu, (44), 171-198. https://doi.org/10.1590/1809-4449201500440171

Sibilia, P. (2016). O show do eu. Contraponto.

Wolf, N. (1992). O mito da beleza: Como as imagens de beleza são usadas contra as mulheres (W. Barcellos, Trad.). Rocco. (Trabalho original publicado em 1990)

Este trabalho está licenciado com uma_Licença Creative Commons - Atribuição 4.0 Internacional. 